\title{
Medicinal Products: Regulation of Biosynthesis in Space and Time
}

\author{
Otto R Gottlieb ${ }^{+}$, Maria Renata de MB Borin
}

\author{
Departamento de Fisiologia e Farmacodinâmica, Instituto Oswaldo Cruz, Av. Brasil 4365, 21045-900 \\ Rio de Janeiro, RJ, Brasil
}

\begin{abstract}
We live in a "Demon-Haunted World". Human health care requires the ever increasing resistance of pathogens to be confronted by a correspondingly fast rate of discovery of novel antibiotics. One of the possible strategies towards this objective involves the rational localization of bioactive phytochemicals. The conceptual basis of the method consists in the surprisingly little known gearings of natural products with morphology, ecology and evolution of their plant source, $i$. e. an introspection into the general mechanisms of nature.
\end{abstract}

Key words: quantitative chemical biology - metabolism - morphology - ecology - evolution

Resistance of pathogens against antibiotics is one of the most relevant medical problems of our times. Caused by a new type of patient taking excessively strong drugs in the treatment of any disease, it is responsible for the frequent and serious infections transmitted in hospitals. Diseases formerly under control such as tuberculosis, gonorrhea and even measles became more difficult to be treated. Old epidemics, such as the medieval bubonic plague, continue to threaten. New epidemics, such as those caused by Aids and the Ebola virus, hit cities and highly degraded environments. A constant war is waged between microbial attack and human defense via the discovery and introduction of new remedies and treatments. Such a passive strategy is dangerous. Indeed, in face of our ignorance about the complex mutual dependence of the beings on Earth, we destroy especially vulnerable microbes on which larger organisms depend, or more directly even these producers of antibiotics themselves. What is going to happen after new antibiotics cease to be discovered at an appropriate rate (Sagan 1996)?

The process of discovery and development of one new pharmaceutical from a single plant species is already far from our capabilities concern-

\footnotetext{
This work was supported by a grant from Academia Brasileira de Ciências, Rio de Janeiro, and by fellowships from Conselho Nacional de Desenvolvimento Científico e Tecnológico, Brasília, Brazil.

${ }^{+}$Corresponding author. Correspondence address: Rua 5 de Julho 323 apt. 1001, 22051-030 Rio de Janeiro, RJ, Brasil.Fax: +55-21-257.1807.E-mail:ogottlieb@abc.org.br Received 28 July 1999

Accepted 20 October 1999
}

ing financing and manpower (McChesney 1995). Hence a comprehensive experimental quest for bioactive compounds would be impracticable, even limiting work to Brazilian flowering plants. The dynamics of their 55,000 species requires an analytical effort of fantastic magnitude. With respect to this number of angiosperm species, Brazil occupies the first place. With respect to the number of published papers on their chemical constituents, Brazil occupies the 17th place (Gottlieb \& Borin 1997a). Considering our very serious losses in biodiversity to exceed vastly the limits of natural sustainability, our plight is understandable. Appropriate financing of our efforts would be helpful, but not sufficient. We need, most of all, coordination of efforts. Our holistic work aims to provide an outline of the basic strategy: the reduction of the problem to a manageable size via understanding of the mechanisms of nature.

The effort requires quantification for the study of compounds or structures and mapping for the study of forms or patterns (Capra 1988). The appropriate methodology, described in our previous articles (Gottlieb 1989, 1990, Gottlieb et al. 1995b, Gottlieb \& Borin 1997b) and books (Gottlieb 1982, Gottlieb et al. 1996b) on quantitative chemical biology, replaces the traditional descriptive approach. "If you know a thing only qualitatively, you know it no more than vaguely. If you know it quantitatively - grasping some numerical measure that distinguishes it from an infinite number of other possibilities - you are beginning to know it deeply. You comprehend some of its beauty and you gain access to its power and the understanding it provides. Being afraid of quantification is tantamount to limiting yourself, giving up on one of the most potent prospects for understanding and changing the world" (Sagan 1997). 
In the following we attempt to clarify the coherence of metabolism (i.e. natural products) with morphology, ecology and evolution through quantitative phytochemistry.

\section{WHAT ARE NATURAL PRODUCTS?}

Natural products may possess medicinal properties, or in general, bioactivity. Hence, in order to discover interesting compounds, all constituents of an organism would have to be studied. This being impracticable, one must try to understand the interrelation of the process with respect to biosynthesis.

Molecular biologists discovered the fundamental building blocks of nature (genes, enzymes). This, however, did not lead to the understanding of the vital, integrative actions of living organisms coordinated by micromolecules, chemical signals made by membrane-bound enzymes. Indeed these membranes are composed of micromolecules (secondary metabolites). Hence, such compounds are most probably waste products of the optimization procedure of membrane construction.

\section{ARE NATURAL PRODUCTS AND MORPHOLOGY CONNECTED?}

Chemosystematics, the correlation of micromolecules and morphology of a cellular network, is conceptually difficult, unless the tridimensional relationship of micromolecules and membranes is evoked. The signal function of molecules is dependent on the geometry of both, metabolites and substrates. Clearly not only the more diverse or numerous the membranes to be bridged, the greater must be the diversification potential of the signal. Such a potential is incorporated to different degrees in organic molecules (i.e. secondary metabolites). The evolutionary developments which led to the origin of the first protists implied the differentiation of intracellular membrane systems capable of synthesizing steroids and polyunsaturated fatty acids and were probably preadaptations for endo- and exocytosis. Extensive plant biosynthetic pathways required the prior evolution of the polygenomic plant cells (circulatory systems in animals). Vascular plants could have evolved only upon the substrata laid down by the prior evolution of structural materials-lignin (cartilage and bone in animals) (Margulis 1981).

Membranes are thus condition sine qua non for the existence of secondary metabolism. For this reason most metabolites exist in plants and fungi. In contrast, only few natural products occur in animals exempt of cell walls, but reappear in segmented insects and porous sponges.

Hence micromolecules, according to their stereochemical fit into cellular receptors, should dem- onstrate variable significance as systematic markers. This point is exemplified for the genus Piper, where in contrast to arylpropanoids, sesquiterpenoids lack coherence with morphological evidence (Borin \& Gottlieb 1997). In this, and in many analogous cases, chemical and/or morphological plasticity may throw doubt on the importance of more detailed taxonomical revisions.

\section{ARE NATURAL PRODUCTS AND ECOLOGY CONNECTED?}

Substantially homogeneous Brazilian ecosystems are separated by heterogeneous boundaries (ecotones). In analogy with phase transitions in the physical sense, or with membranes on the cellular scale, these "tension zones" are endowed with profound creative potential. This fact can be appreciated examining e.g. molecular profiles calculated for 13 regions of the Amazonian rain forest and eight regions of the central plateau's shrubby savanna ("cerrado") (Gottlieb \& Borin 1994, 1997a). Predominance of occurrence and diversification are noted for neolignans, benzylisoquinoline alkaloids and lignans, all shikimate derived, and for polyacetylenes, steroids and pyrrolizidine alkaloids, all acetate derived, in the former and the latter ecosystems, respectively. The dramatical disjunction between 10 and $15^{\circ}$ southern latitude neatly exemplifies a tension zone's creative potential (Fig. 1).

The Lauraceae were selected to illustrate the ecotone effect on a worldwide longitudinal scale. The genera of this family contain in Asia chiefly benzylisoquinoline alkaloids and in America chiefly neolignans. Crossovers in predominance of

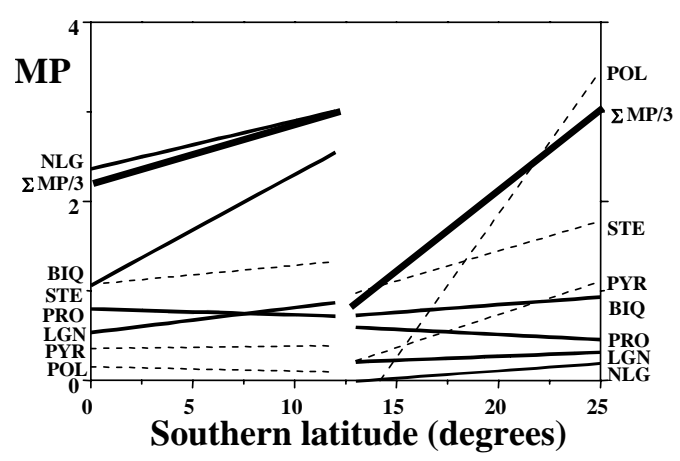

Fig. 1: linear regression lines for correlations of metabolic profiles of 7 micromolecular categories and southern latitudes for 13 floristic inventories of rain forest $\left(0-10^{\circ}\right)$ and 8 floristic inventories of savanna $\left(15-23^{\circ}\right)$ (Gottlieb \& Borin 1994). Shikimate profiles and proanthocyanidins (PRO), of mixed biosynthesis, are represented by thin lines, acetate profiles are represented by dashed lines and the total of metabolic profiles ( $\Sigma$ MP) are represented by thick lines. For abbreviations see legend to Fig. 2. 
these chemical categories occur in the intermediate regions of their spatial radiations, via an equatorial route for genera of the Perseae tribe, and an Australian route for genera of the Laureae tribe (Pagotto et al. 1998).

\section{ARE NATURAL PRODUCTS AND EVOLUTION CONNECTED?}

All the chemical categories mentioned so far are formed either on the shikimate route or on the acetate route, or on both. The former predominates in the most primitive angiosperm subclass Magnoliidae, where most plants are woody. The second one predominates in the most highly evolved angiospermous Asteridae, where most plants are herbaceous. The last one predominates in the subclasses of intermediate evolutionary status, Hamamelidae, Dilleniidae and Rosidae, where most plants are shrubs. Metabolic, morphologic and ecogeographic characteristics also demonstrate the relative lack of uniformity of the HDR-complex (Gottlieb \& Borin 1998a).

A biosynthetic scheme of intermediate metabolism indicates the branching points, either on the shikimate route or on the acetate route, which lead to the different categories of natural products (Fig. 2). Impact of the shikimate and acetate pathways generates products such as flavonoids and stilbenoids, many bearing terpenoid side chains. One of the bifurcation points concerns the derivation of neolignans, where the production of shikimate derivatives seems to have been exhausted, and evolutionary canalization leads back first to benzylisoquinoline alkaloids and then successively over complex indole alkaloids to shikimate. This liberates gallic acid. Activator of phenylalanine ammonia lyase (Boudet et al. 1971), gallic acid causes negative feedback of the shikimate route, enhancing the production of cinnamic acids and hence of lignins. Another bifurcation point concerns the liberation of excess oxaloacetic acid into the cytoplasm. The consequent inversion of the Krebs cycle produces active (partially reduced) oxygen, i.e. superoxide or hydrogen peroxide, responsible for lignification (Higuchi 1985). Such kinetic alterations via environmental conditions (e.g. variations in light and temperature) indicate the existence of a kind of metabolic memory in plants (Jantsch 1985).

Systematic observations on lignification in angiosperms lead to the expectation that a Woodiness Index (WI $=100$ - HI, i.e. Herbaceousness Index) should be indicative of the evolutionary status of angiosperm families (Gottlieb et al. 1995b), albeit only in the case of substantially gallate free taxa. Indeed, a good correlation of HI and the Sporne Index (SI, the sole numerical index representing evolutionary advancement for angiosperms) (Sporne 1980) was observed for medicine and food plants (supposedly containing only minimal quantities of tannins) in use by three In-

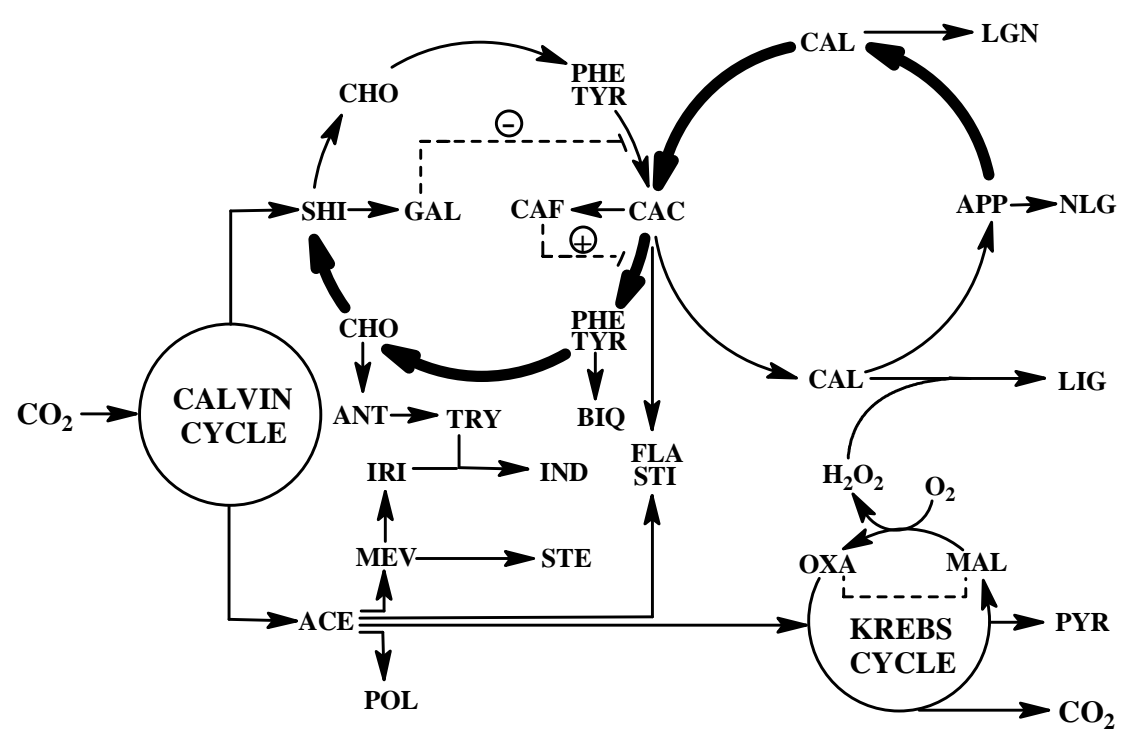

Fig. 2: biosynthetic (thin arrows) and evolutionary (thick arrows) processes (i.e. activation/inhibition) regulated by negative ( $\ominus$ ) and positive $(\oplus)$ feedbacks leading to selected categories of secondary metabolites in angiosperms. SHI shikimic acid, CHO chorismic acid, PHE phenylalanine, TYR tyrosine, CAC cinnamic acids, CAL cinnamyl alcohols, APP allyl- and propenylphenols, GAL gallic acid, CAF caffeic acid, ANT anthranilic acid, TRY tryptophane, IND indole alkaloids, BIQ benzylisoquinoline alkaloids, LGN lignans, LIG lignins, NLG neolignans, ACE acetic acid, MEV mevalonic acid, POL polyacetylenes, PYR pyrrolizidine alkaloids, STE steroids, IRI iridoids; FLA flavonoids, STI stilbenoids, OXA oxalic acid, MAL malic acid. 
dian societies of Amazonia (see below).

Calculation of the proportion of shikimate/acetate derivatives allows modelling of the power of shikimate $v s$. acetate attractors, revealing metabolic plasticity of angiosperm subclasses close to the maximum of instability (50\%), and hence complexity (Gottlieb \& Borin 1998b). This can be envisaged even more clearly comparing such models for angiosperms with and without gallic acid (Fig. 3 ). In the first case, strong diversification of acetate derivatives occurs, leading to trends of diminishing lignification (Fig. 3a). In the second case, strong diversification of shikimate derivatives occurs, leading to trends of increasing lignification (Fig. 3b). Modelling strengthens the expectation that the occurrence of natural products will soon be predictable qualitatively and quantitatively.

In angiosperms evolution of compounds within shikimate derived metabolic categories obeys identical kinetics: a long series of more primitive families is characterized by a slowly increasing number of compounds. This induction of occurrence is followed by a maximum prior to a rapid decrease in direction of the extinction of the metabolic category. Identical behaviour is observed for acetate derived metabolic categories (Gottlieb \& Borin 1998b). The substitutions of the metabolic categories show great analogy with substitutions in dominance of several groups of organisms. In this case

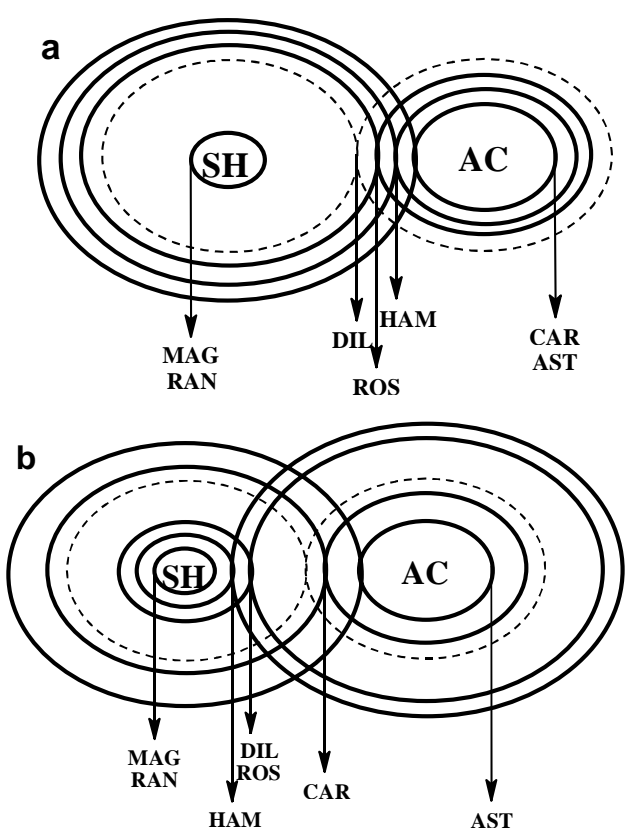

Fig. 3: mechanical models representing shikimate $(\mathrm{SH})$ and acetate (AC) as metabolic attractors for angiosperm subclasses in absence (a) and in presence (b) of gallic acid derivatives. MAG Magnoliidae, RAN Ranunculidae, CAR Caryophylidae, HAM Hamamelidae, DIL Dilleniidae, ROS Rosidae, AST Asteridae. relatively long periods of quietude, when little novelties occur, are followed by episodes of relatively abrupt modifications, when environment and its inhabitants are replaced by some new system (Day 1979, Gottlieb \& Borin 1998c).

The evolutionary metabolic lineages are oxidative. This was shown by indirect and direct criteria. The indirect one referred to the absence of chemical lineages in polyphenol-antioxidants (e.g. gallates) containing families (Zocher et al. 1998), very strongly for shikimate derived categories and less strikingly for acetate derived categories (Gottlieb \& Kaplan 1993, Gottlieb et al. 1995b). The direct evidence referred to positive correlations of mean oxidation parameters of micromolecules within metabolic categories $v s$ the evolutionary sequence of families of a lineage (e.g. benzylisoquinolines of increasing oxidation value vs lower WI, i.e. higher HI, of Magnoliidae families) (Gottlieb 1982, 1989, Gottlieb et al. 1995b, 1996b). True, gradual oxidation of natural products is a powerful evolutionary phytochemical marker.

A full view of the situation is featured on a Dahlgrenogram (Fig. 4), where each area representing an angiospermous superorder is divided in sections representing orders. Families of orders heavily charged with polyphenols $(\mathrm{G})$ do not participate in oxidative metabolic lineages. Such lineages comprising e. g. polyacetylenes, pyrrolizidine alkaloids, iridoids and cucurbitacins, although represented by a very few little oxygenated compounds in Magnoliidae, start conspicuously in Dilleniidae and via Rosidae attain highest structural variation in Asteridae. The evolutionary polarity of the lineages toward the periphery of the diagram is indicated by the increase of structural diversity, evaluated by the size of the letters.

An example based on regulation of medicinal products biosynthesis refers to trends of plant use by three indigenous human societies in Amazonia (Gottlieb \& Borin 1997b, Gottlieb et al. 1995a). Analyses reveal a common trend: more primitive plant species are used as foods and more recently evolved plant species are used as medicines. Precisely the same regularities are noted for plant use by three species of nonhuman primates in Amazonia (Gottlieb et al. 1996a). This inspired the question: who learned what from whom?

One hypothesis to explain the observations is related to the presence of toxic constituents in the more advanced species, in contrast to astringent polyphenols in the more primitive ones. Thus a certain degree of astringency might indicate absence of harmful chemicals, and even stimulate ingestion for humans and monkeys alike. 


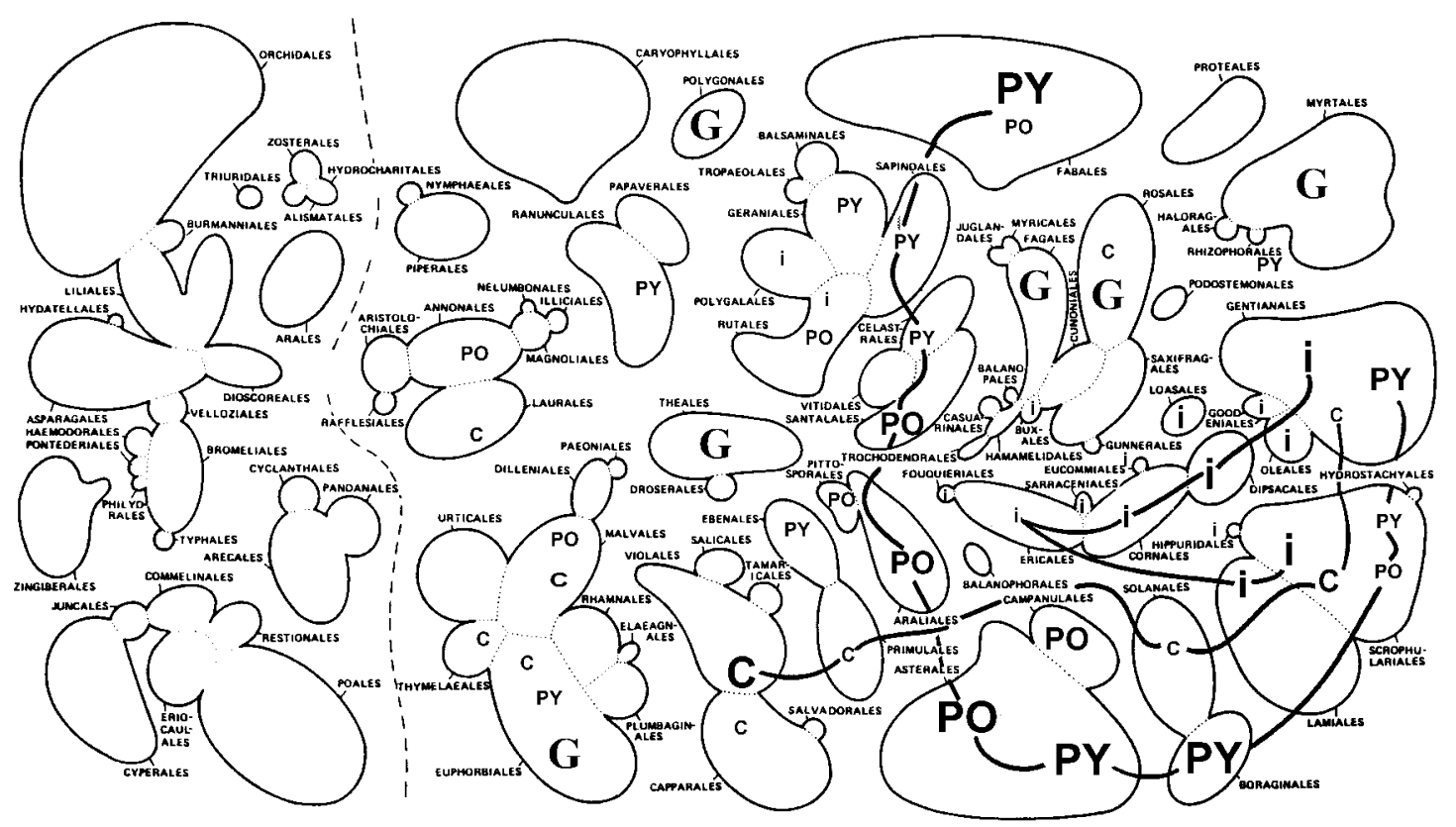

Fig. 4: distribution of gallic acid (G) and of oxidative chemical lineages on a Dahlgrenogram (Dahlgren 1980). C cucurbitacins, I iridois, PO polyacetylenes, PY pyrrolizidine alkaloids.

\section{CONCLUSION}

Biological phenomena, of molecular, cellular, morphologic and ecogeographic nature, are expressed in space by transition of boundaries, generating the creative forces responsible for biodiversity, and in time by modulation of rythms, generating the kinetic variations responsible for biocomplexity. Thus it is possible to qualify metabolic categories with respect to their systematic relevance and position, and clarify insights into chemical lineages within angiosperms for the benefit of the preselection of taxa with special organic structures.

\section{REFERENCES}

Borin MR de MB, Gottlieb OR 1997. Químico-biologia quantitativa: IV. Piper, oxidação metabólica versus complexidade morfológica. In Abstracts of XIX Reunião Anual sobre Evolução, Sistemática e Ecologia Micromoleculares, Rio de Janeiro, CONF-25.

Boudet A, Ranjeva R, Gadel P 1971. Propriétés allostériques des deux isoenzymes de la phényl-alanine-ammoniaque lyase chez Quercus pedunculata. Phytochemistry 10: 997-1005.

Capra F 1988. The Turning Point. Bantam Books, Toronto, p. 77.

Dahlgren RMT 1980. A revised system of classification of the angiosperms. Bot J Linn Soc 80: 91-124.

Day W 1979. Genesis on Planet Earth. The House of Talos Publishers, East Lansing, p. 387.

Gottlieb OR 1982. Micromolecular Evolution, System- atics and Ecology. An Essay into a Novel Botanical Discipline, Springer Verlag, Berlin, 170 pp.

Gottlieb OR 1989. The role of oxygen in phytochemical evolution towards diversity. Phytochemistry 28: 2545-2558.

Gottlieb OR 1990. Phytochemicals: differentiation and function. Phytochemistry 29: 1715-1724.

Gottlieb OR, Borin MR de MB 1994. The diversity of plants. Where is it? Why is it there? What will it become? An Acad Bras Ci 66 (Suppl. 1): 55-83.

Gottlieb OR, Borin MR de MB 1997a. Natural products research in Brazil. Ciênc Cult 49: 315-320.

Gottlieb OR, Borin MR de MB 1997b. Shamanism versus science in the search for useful natural products,. In L Verotta, Virtual Activity, Real Pharmacology Different Approaches to the Search for Bioactive Natural Compounds, Trivandrum, Research Signpost, p. 123-135.

Gottlieb OR, Borin MR de MB 1998a. Natural products and evolutionary ecology. Pure Appl Chem 70: 299302.

Gottlieb OR, Borin MR de MB 1998b. Evolution of angiosperms via modulation of antagonisms. Phytochemistry 49: 1-15.

Gottlieb OR, Borin MR de MB 1998c. Quantitative chemical biology. IV. Analogies of metabolical mechanism and biological evolution. An Acad Bras Ci 70: 719-726.

Gottlieb OR, Borin MR de MB, Bosisio BM 1995a. Chemosystematic clues for the choice of medicinal and food plants in Amazonia. Biotropica 27: 401406.

Gottlieb OR, Borin MR de MB, Bosisio BM 1996a. 
Trends of plant use by humans and non-human primates in Amazonia. Am J Primatol 40: 189-195.

Gottlieb OR, Borin MR de MB, Kaplan MAC 1995b. Biosynthetic interdependence of lignins and secondary metabolites in angiosperms. Phytochemistry 40: 99-113.

Gottlieb OR, Kaplan MAC 1993. Phytochemical evolution: the redox theory. Nat Prod Lett 2: 171-176.

Gottlieb OR, Kaplan MAC, Borin MR de MB 1996b. Biodiversidade. Um Enfoque Químico-Biológico, UFRJ, Rio de Janeiro, 267 pp.

Higuchi T 1985. Biosynthesis of lignin. In T Higuchi, Biosynthesis and Biodegradation of Wood Components, Academic Press, Orlando, p. 141-160.

Jantsch E 1985. The Self-Organizing Universe. Pergamon Press, Oxford, p. 221.

Margulis L 1981. Symbiosis in Cell Evolution. Freeman \& Co., San Francisco, p. 340-341.

McChesney JD 1995. The promise of plant-derived natural products for the development of new pharmaceuticals and agrochemicals. In PR Seidl, OR
Gottlieb, MAC Kaplan (eds), Chemistry of the Amazon. Biodiversity, Natural Products, and Environmental Issues, American Chemical Society Symposium series 588, Washington, D.C., p. 66-78.

Pagotto CLA da C, Barros JRT, Borin MR de MB, Gottlieb OR 1998. Quantitative chemical biology. II. Chemical mapping of Lauraceae. An Acad Bras Ci 70: 705-709.

Sagan C 1996. The Demon-Haunted World. Brazilian edition: O Mundo Assombrado pelos Demônios: a Ciência Vista como uma Vela no Escuro, Companhia das Letras, São Paulo, p. 25.

Sagan C 1997. Billions and Billions: Thoughts on Life and Death at the Brink of the Millennium. Random House, New York, p. 21.

Sporne KR 1980. A re-investigation of character correlations among dicotyledons. New Phytol 85: 419499.

Zocher DHT, Borin MR de MB, Gottlieb OR 1998. Quantitative chemical biology. III. Chemical mapping of Dilleniidae. An Acad Bras Ci 70: 711-717. 